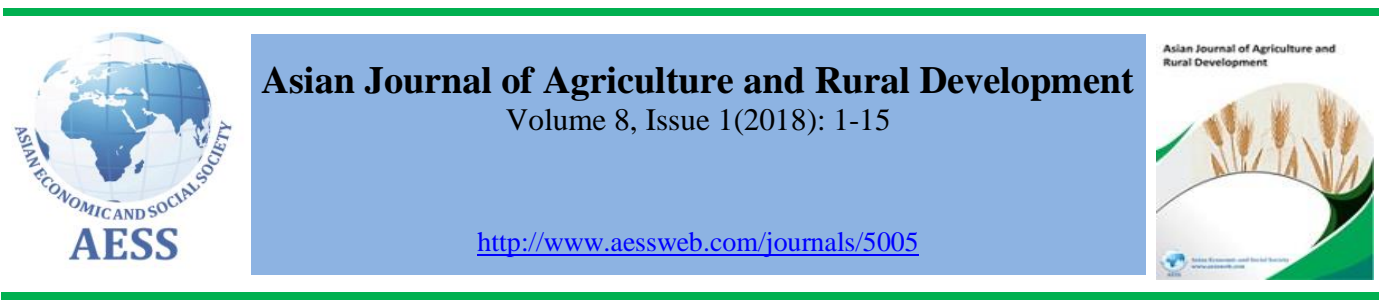

\title{
ROLE OF PARTICIPATORY VIDEOS IN ECONOMIC EMPOWERMENT OF RURAL WOMEN: A CASE STUDY FROM BANGLADESH
}

\author{
Khatun, T. ${ }^{\mathrm{a}}$ \\ Sarker, M. A. ${ }^{\text {b }}$ \\ Rahman, M. H. ${ }^{b}$ \\ ${ }^{\mathrm{b}}$ Department of Agricultural Extension Education, Bangladesh \\ Agricultural University, Mymensingh, Bangladesh. \\ ${ }^{a}$ Department of Agricultural Extension, Ministry of Agriculture, \\ Government of the People's Republic of Bangladesh, \\ Bangladesh.
}

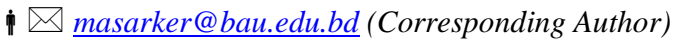

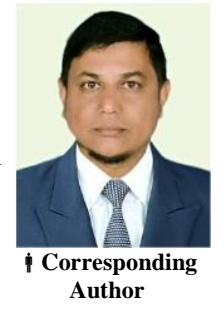

ARTICLE HISTORY:

ABSTRACT
The present study was intended to assess function of participatory
videos in improving economic empowerment of the rural women.
Pragmatic information for the study was composed from 65 randomly
selected rural women from the study villages using structured interview
schedule. The result of the study showed that over half ( 56.9 percent)
of the respondents had medium income improvement due to
participation of IGAs like preparation of vermi-compost, preparation of
botanical pesticide, home gardening, safe food processing and filming
(recording of local events) as introduced by participatory video
programs. The result of the study also illustrated that the top mass
(70.76 percent) of the respondent women had participation in
homestead gardening after joining with video programme while it was
less than half ( 47.69 percent) before joining to video programme.
Findings also showed that the half (61.6 percent) of the women had
medium to soaring participation in family decision making method.
Additionally the study discovered so as to out of the seven selected
socio-economic characteristics of the women except age all the
variables have significant positive relationship with their economic
empowerment.

Received: 25-Apr-2018

Accepted: 01-Aug-2018

Online Available: 22-Aug-

2018

\section{Keywords:}

Economic empowerment, participatory video,

rural women

ABSTRACT Author

The present study was intended to assess function of participatory videos in improving economic empowerment of the rural women. Pragmatic information for the study was composed from 65 randomly selected rural women from the study villages using structured interview schedule. The result of the study showed that over half (56.9 percent) participation of IGAs like preparation of vermi-compost, preparation of botanical pesticide, home gardening, safe food processing and filming (recording of local events) as introduced by participatory video programs. The result of the study also illustrated that the top mass (70.76 percent) of the respondent women had participation in homestead gardening after joining with video programme while it was less than half (47.69 percent) before joining to video programme. Findings also showed that the half (61.6 percent) of the women had medium to soaring participation in family decision making method. Additionally the study discovered so as to out of the seven selected variables have significant positive relationship with their economic empowerment.

\section{Contribution/ Originality}

The present study has taken the challenge of combining video-mediated information with income generating activities of the through rural women which has shown its role in improving their economic capacity was well as taking part of the women in decision making process which ultimately contributing in their empowerment process.

DOI: 10.18488/journal.1005/2018.8.1/1005.1.1.15

ISSN (P): 2304-1455/ISSN (E):2224-4433

How to cite: Khatun, T., Sarker, M. A. and Rahman, M. H. (2018). Role of participatory videos in economic empowerment of rural women: a case study from Bangladesh. Asian Journal of Agriculture and Rural Development, 8(1), 1-15.

(C) 2018 Asian Economic and Social Society. All rights reserved. 


\section{INTRODUCTION}

Women constitute nearly half (male- 51 percent and female-49 percent) of the people and half of its prospective, who are the co-builders of the country (BBS, 2016). But women are underprivileged everywhere in the world, especially in mounting countries like Bangladesh (Hoque and Itohara, 2008). The existence of women in the country is subjugated by a meticulous societal arrangement. Customarily, a woman in Bangladesh originates her position from her family (Kabeer, 2001). Inequality between men and women in schooling, health, service and earnings, power over material goods, personal safety and contribution in political process disclose that women are depressed and less empowered, which confines the country's capability to attain its full prospective (Parveen and Leonhauser, 2004). Aggression in opposition to women is a regular occurrence in rural areas of the country. Domination, murder, abduction, trafficking, rape, acid throwing etc. against women has almost become regular part of life (Begum, 2005). At present Bangladesh is one of the noteworthy female-violence precious countries due to lack of empowerment and social agreement (UNDP, 2010).

Despite nation and global level interferences, the position of women in the country is not so far comfortable. Although two women Prime Ministers have ruled Bangladesh Government for last 25 years and the opposition leaders in the parliament were also women, this does not imitate the gender symphony in participation and economic donation at household level (MoWCA, 2016).

In the recent time, women contribute significantly to their families and to the economy of the country but their position have been graded the lowly in the world by reason of some indicators relating to healthiness, wedding, offspring, schooling, service and shared excellence (UNDP, 1997). Though 'Bangladesh constitution' promises identical constitutional rights to male and female in the country (GOB, 2015), but in family connections such as wedding, separation, guardianship, protection, legacy and laws distinguishes aligned with women. This gender prejudice is pervasive in all places and at all levels, as pointed out by official statistics on health, nourishment, schooling, employment, and political participation (Bhaumik et al., 1996).

Thus, the inadequate access to all the capital resources, especially the lack of human, financial and social capital is hindering the upgrading in the worth of life for the women in rural areas of the country (Hoque et al., 2010). Rural women are bound by these inadequacies that leave them as less empowered in the family as well as in the society. The improvements of the livelihood of these resource-poor women are possible to a greater extent by their capacity building. However, the involvement of women in different organizations can improve their skill, create employment opportunities, and improve their leadership capacity which is very essential for their economic empowerment. But in reality, Bangladeshi rural women do not have admission in such organizations.

Now-a-days, rural women throughout Asia and the pacific region make critical economic contribution to households through participatory video program. Participatory video traditionally supports an empowering procedures where society people 'move ahead in iterative series of filmingreviewing' to 'create film descriptions that speak what folks who take part in the progression really desire to talk, in a way they feel is perfect' (Kindon, 2003). Participatory Video would be useful for information and communication technology (ICT) to facilitate capacity development of the resource poor women in Bangladesh (Chowdhury et al., 2011).

In the context of Bangladesh, the factors determining work and economic contribution of the rural women can be grouped into two broad categories, namely: those embedded in the community and those embedded within the households. Thus, the study was aimed to check the role of participatory video program in economic empowerment of rural women. 
Currently women are mostly deprived in Bangladesh. Their work is not properly recognized. But they have the potentiality to do many income generating activities (Parveen and Leonhauser, 2004). Participatory video programs aim at developing the overall sphere of community at grass root level by empowering rural women and mainstreaming them in household economic contribution. Participatory video permits for women empowerment in a range of ways. Papa et al. (2000) reported that empowerment of women is connected to sharing feelings (connectedness), assessing individual measures for relationships and environmental shock (integrative thoughts) and serving one others in the course of joint stroke (mutual enactment). A large number of women also take part in these development programs. For true development of rural women, participatory video programs have to find out the level of empowerment of the beneficiaries and taken special program for low empowered women. To identify the level of empowerment and formulate development strategies, it is necessary to conduct a study on empowerment of the women in the perspective of countryside of Bangladesh.

The focal point of the study is to determine and describe the empowerment of rural women through Income Generating Activities (IGAs) under participatory video programs. The following specific objectives are undertaken for this study:

i. To appraise the form and degree of women's involvement in income generating actions along with their contribution in household income through participation in participatory video program;

ii. To measure the role of participatory videos in economic empowerment of the women in the study regions; and

iii. To investigate the associations stuck between the selected characters of the rural women and their economic empowerment. The characters are: age, personal education, educational status of spouse/household head, personal asset, communication exposure, organizational participation and women friendly environment existing in the community.

\subsection{Theoretical framework of the study}

Utilizing videos in agricultural extension works is not just latest, yet the idea of participatory video is truly innovative in the perspective of Bangladesh. Participatory video is a type of participatory media wherein a cluster or group of people forms their personal film. The concept at the back this is that creation of a video is simple and reachable, and is a grand means of bringing people collectively to discover subjects, voice apprehensions or merely to be stimulated and say to tales. However, the selected rural women were from marginalized families along with poor literacy, no scope of employment, little control over resources. Thus, they were economically and socially less empowered.

As participatory video process found as very effectual in authorizing, facilitating a cluster or group of people to get their own stroke to resolve their personal tribulations (Van Mele, 2006 and Zossou et al., 2009). Thus, participatory video approach was taken on to develop economic empowerment of this deprived portion of women.

According to Lunch and Lunch (2006) participatory video work in the following way-

- Building of individual skills of the society and other fascinated players to utilize the technology

- Exploring of the catalysts who watch their function as "co-learner"

- Developing associations and recognizing the progress troubles through appealing in conversation with the contributors and by means of participatory gears personalized to the situation

- Petite film and communication equipped and recorded with and by the contributors

- Every day broadcasting of video recording with the neighborhood

- Approving a society-led education, giving out and swap movement

- Finished film is able to serves as a foundation for knowledge and share between ranges of unlike target people. 
Both of the project villages are famous agrarian community in the area. Farmers of these villages were entirely reliant on use of synthetic fertilizers and pesticides during growing vegetables and other crops. Due to excessive use and usual cost hike of agro-chemicals lots of them led to give up agriculture in the current years. Thus the plan got the idea to train up the local farmers particularly female concerning using of substitutes of agro-chemicals.

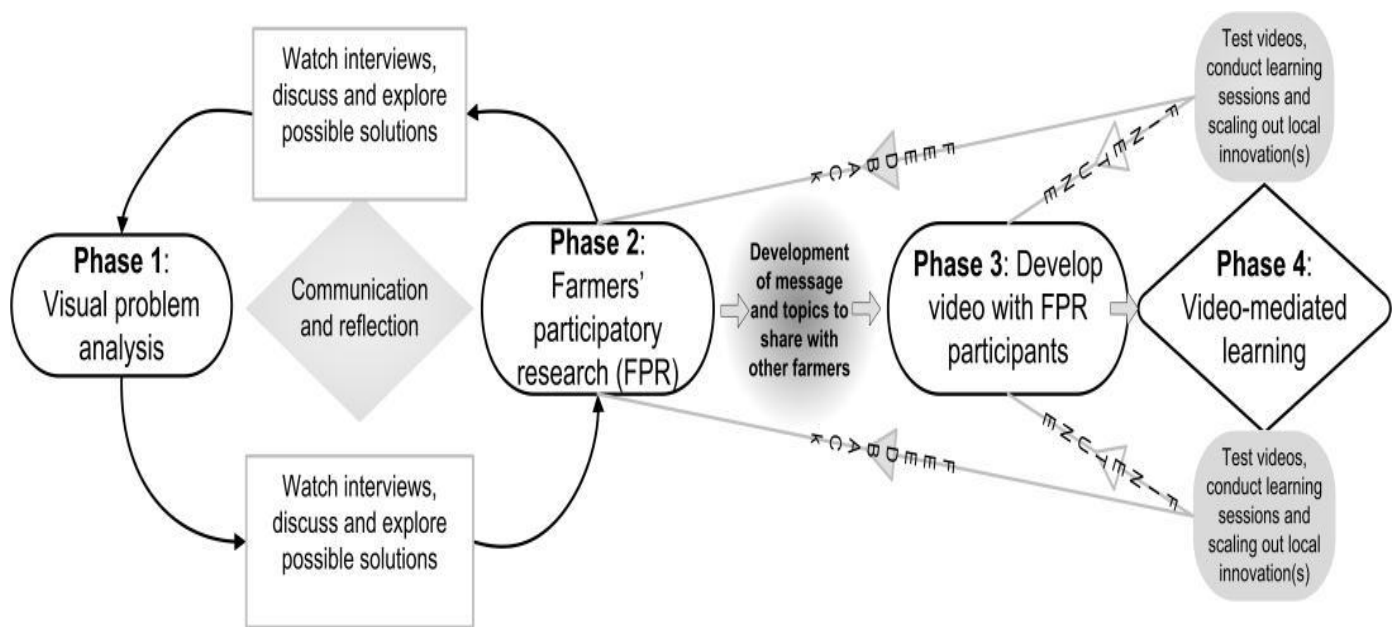

Figure 1: Phases to combine famers' participatory research with video to scale out farmers' innovation

After participation in the training programmes, PV team members determined on participatory investigation to resolve their troubles of synthetic pesticides and prepare a botanical pesticide from local plants for managing insect and disease pests in their crops (Van Mele, 2006 and Zossou et al., 2009).

The method of the competence construction is associated with participatory research of the farmers (FPR) philosophies. The Participatory video group acts together with beneficiaries to recognize neighboring innovations and carry out pertinent experiment. For this venture the rural women were employed with selected issues:

1. Safe vegetable cultivation

2. Production of vermi-compost ;

3. Production of botanical pesticide;

4. Filming (video recording)

5. Safe food processing;

6. Handicraft making;

7. Homestead gardening. 


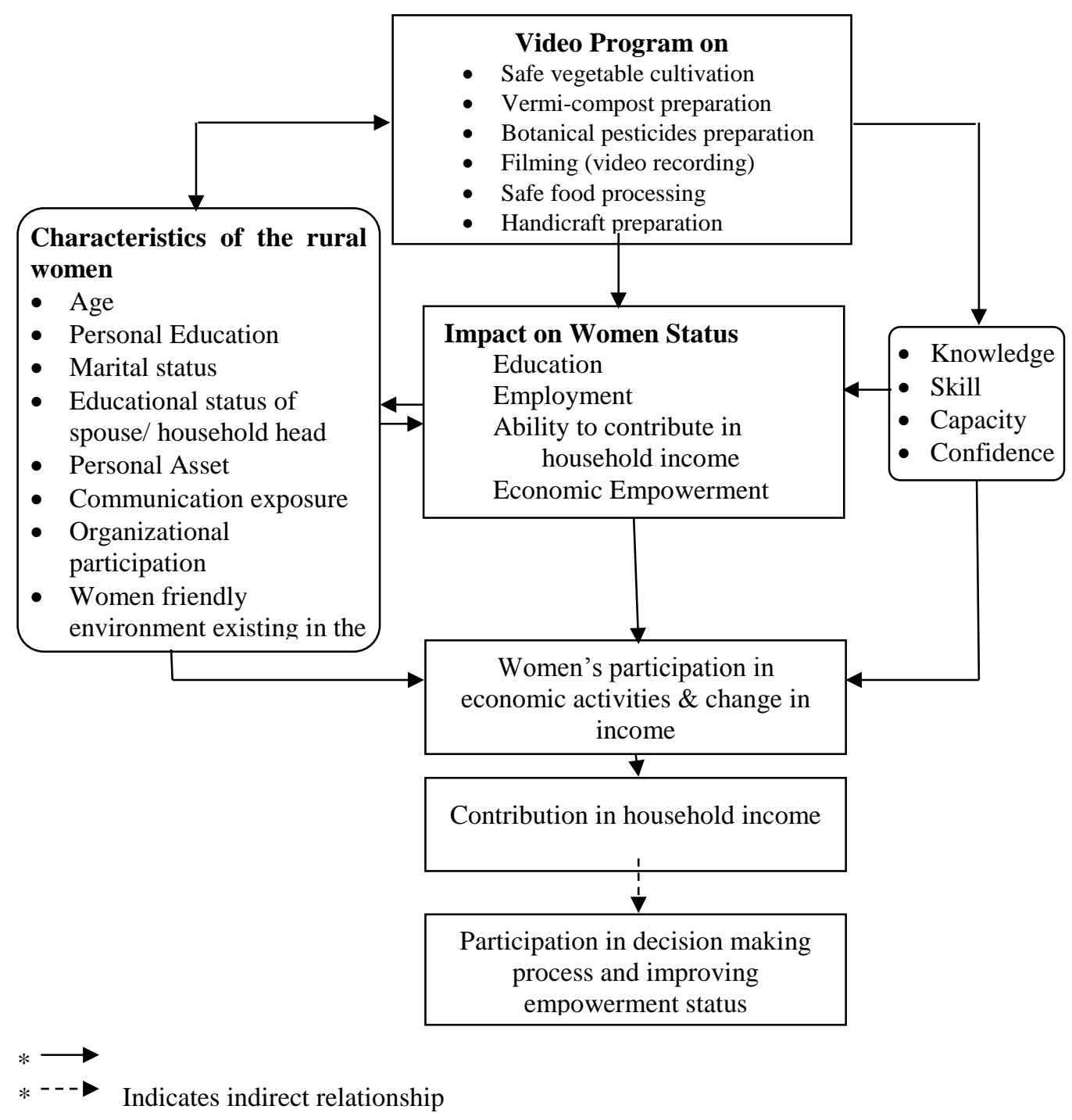

Figure 2: Conceptual framework of the study

\section{METHODOLOGY}

This study was performed in the three selected villages explicitly Kamarpara and Fulkut villages of Shajahanpur upazila (sub-district) and Bangra village of Sherpur upazila (sub-district) under Bogra district of Bangladesh. 


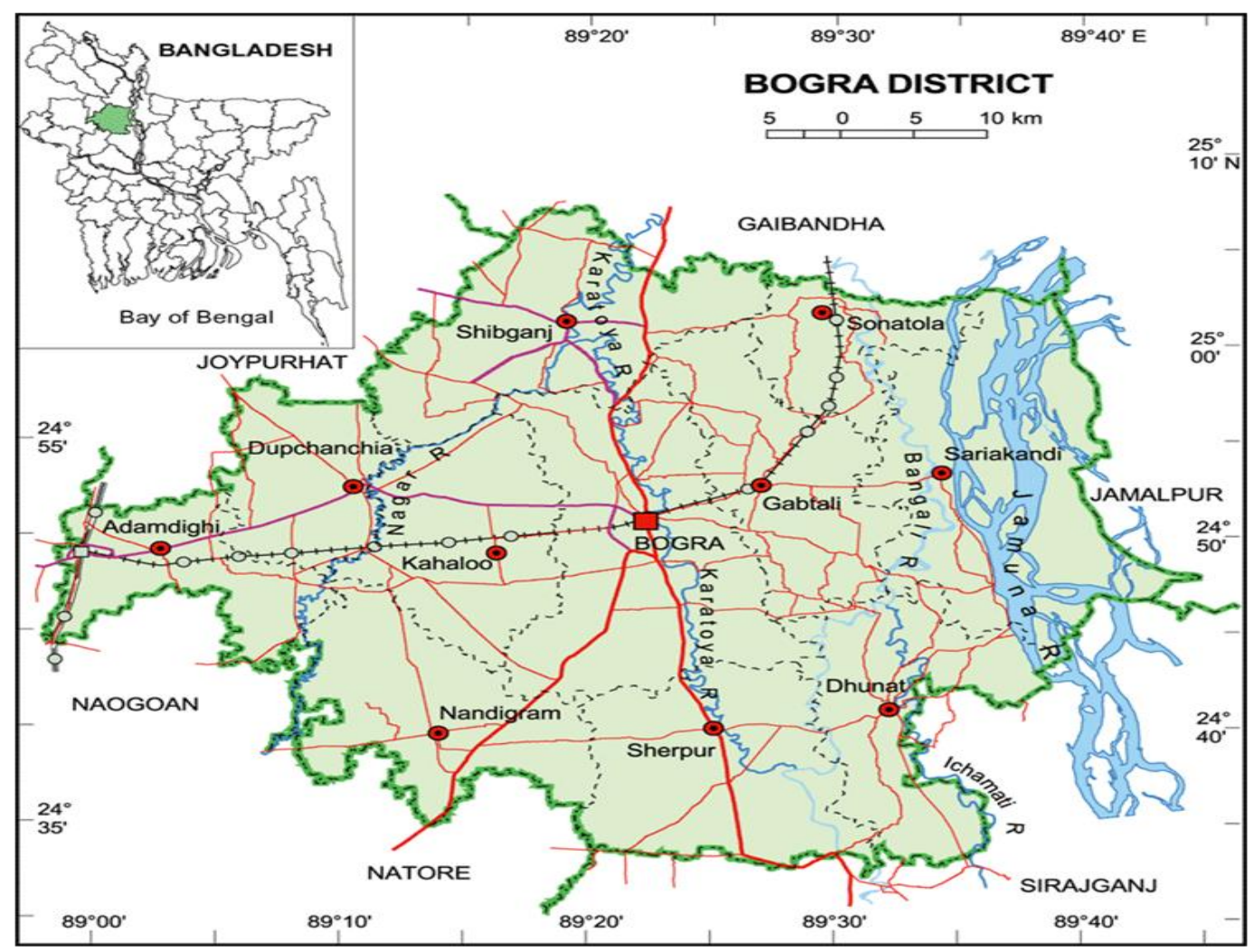

Figure 3: Map of the study area

There were a total amount of 420 rural women from the three selected villages who were involved with participatory video programme jointly operated by the Department of Agricultural Extension Education, Bangladesh Agricultural University (BAU), Mymensingh and Rural Development Academy (RDA), Bogra. These 420 women composed the population of the study. Amongst this population around 15 percent (65 housewives) were chosen randomly as sample of the proposed study and empirical data were obtained from them (detailed shown in Table 1). A structured interview schedule was prepared taking into accounts of the objectives of the study. An interview schedule was pre-tested with 10 women and modify accordingly based on the responses of the respondents. At the next step pertinent data were obtained from the respondent rural women following the method of personal interviewing from 05-23 September, 2014. Collected data were coded, categorized and analyzed properly based their nature. SPSS 16 version software was used to analyze the data. Economic empowerment of the rural women was the focal point variable of the study and was considered as change in income.

Table 1: Allocation of the population and sample of study

\begin{tabular}{lccc}
\hline \multirow{2}{*}{ Name of the upazilas } & Name of the villages & \multicolumn{2}{c}{ Number of rural women } \\
& Kopulation & Sample Size \\
\hline \multirow{2}{*}{ Shajahanpur } & Fulkut & 174 & 25 \\
Sherpur & Bangra & 125 & 20 \\
Total & & 121 & 20 \\
\hline
\end{tabular}

Due to involvement in participatory video programme rural women of the study areas took part in some income generating activities (IGAs) for instance safe vegetable cultivation, preparation of 
vermi-compost, preparation of botanical pesticide, filming of local events, safe food processing, handicraft preparation and homestead gardening etc. Respondents were inquired for their extent of involvement in IGAs and upon their involvement respective income was figured out. Respondent's participation in above mentioned IGAs was measured for before and after introducing the participatory videos as a means of income earning.

Upon their involvement in IGAs for both the periods of before and after introduce by the video mediated extension programme, their incomes was figured out for the respective respondents. Through participation in such activities rural women are capable to earn more income as compared to before participation that called income change. As a consequence, they become capable to donate in family income as well as involvement in family verdict process. When a woman earns more income due to participation of such types of activities then they become more capable to contribute in household income as well as participation in family decision making process compared to before participation. As a result, they become more economically empowered and it was measured by ' 000 ' BDT (Bangladeshi currency).

Additionally women's contribution in household income was also measured as contributed in seven different items of family expenses as compared to before joining in participatory video programme. Upon their contribution in household income for both the periods of before and after the videos introduction, their income was figured out for the respective respondents. It was measured by ' 00 ' BDT. However, a woman's decision-making ability of was measured by asking nine aspects related to making decisions in her family by using a 4-point ranking scale. A respondent was asked to indicate her level of involvement in household decision making process against each of the statement along with a 4-point continuum: high participation, medium participation, low participation and no participation while the weightage were assigned as $3,2,1$, and 0 respectively.

\section{RESULTS AND DISCUSSION}

\subsection{Socio-economic characteristics of the rural women}

In the study there were seven chosen characteristics of the rural women. The selected characters were: age, personal education, educational status of spouse/household head, personal asset, communication exposure, organizational participation and women friendly environment exist in the community. The findings of the selected characteristics of the women are presented in Table 2 .

Table 2: Main features of the chosen characteristics of the rural women

\begin{tabular}{lccccc}
\hline Characteristics & $\begin{array}{c}\text { Scoring } \\
\text { System }\end{array}$ & $\begin{array}{c}\text { Possible } \\
\text { Range }\end{array}$ & $\begin{array}{c}\text { Observed } \\
\text { Range }\end{array}$ & Mean & SD \\
\hline Age & $\begin{array}{c}\text { Actual } \\
\text { years } \\
\text { Years of }\end{array}$ & Unknown & $18-60$ & 30.2 & 8.28 \\
\hline $\begin{array}{l}\text { Personal education } \\
\text { Years of }\end{array}$ & Unknown & $0-16$ & 6.32 & 3.76 \\
$\begin{array}{l}\text { Educational status of } \\
\text { spouse or household head }\end{array}$ & $\begin{array}{c}\text { Schooling } \\
\text { Sc00'Tk. }\end{array}$ & Unknown & $0-16$ & 6.89 & 3.73 \\
$\begin{array}{l}\text { Personal assets } \\
\begin{array}{l}\text { Communication exposure } \\
\text { Organizational }\end{array}\end{array}$ & Scale score & $0-48$ & $5-5000$ & 101.2 & 73.78 \\
$\begin{array}{l}\text { participation } \\
\begin{array}{l}\text { Women friendly } \\
\text { environment }\end{array}\end{array}$ & Scale score & $0-12$ & $1-10$ & 20.03 & 5.42 \\
\hline
\end{tabular}

*SD stands for standard deviation 
Table 2 shows that the age of the rural women varied between 18 to 65 years. The average age of the women was 30.20 years with standard deviation of 8.28. On the basis of their age, the women were categorized into three categories: 'young (up to 35)' 'middle aged (36 to 50)' and 'old (above 50)' and shown in Figure 4. Figure 4 demonstrate that the highest majority ( 84.6 percent) of the respondents were young compared to 12.3 percent of the respondent women were middle aged and only 3.1 percent were old. Young aged are generally more amenable to new ideas and practices.

As participatory is a highly modern ICT tools thus young women were relatively more interested compared to old and middle aged women. Young women maintain better communication with various information sources including social networking available in the rural areas. It is natural that young people have affinity to be in touch with various information sources for getting necessary information regarding production, health, family planning as well as current events. Similar observation was found by Biswas (2002), Naoroze (2004) and Sarker (2005).

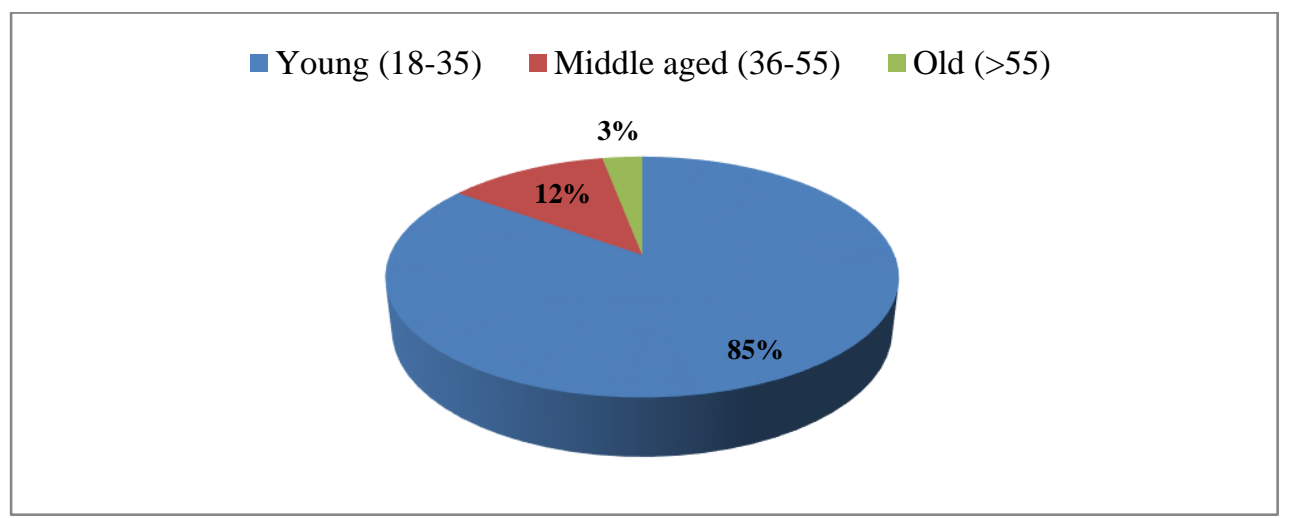

\section{Figure 4: Distribution of the respondent women on the basis of their age}

Result of the study also exposed that the level of education of the rural women ranged between 0 to 18 years of schooling, with an average educational score of 6.32 with a standard deviation of 3.76. On the basis of their years of schooling, the respondents were grouped into four categories: can sign only (0.5); primary education (1-5); secondary education (6-10)'; 'higher secondary education and above (>11) shown in Figure 3. It is evident from Figure 3 that the less than half (42 percent) of the respondent women had secondary education while around one-third (32npercent) of them had primary education. Figure 3 also exhibits that a significant portion (18.5 percent) of the respondents do not have functional literacy but can sign only. It was evident from Figure 5 that 7.7 percent of the respondent women have higher education. However, the rate of literacy of the country is 53 percent (BBS, 2016). Thus, the findings indicate that the literacy rate in the study area seems to be higher than that of state average. Similar finding was also reported by Biswas (2002) and Sarker (2005).

The level of education of the women's spouse/household head ranged from 0 to 18 years of schooling and the average educational score of the spouse was 6.89 with a standard deviation 3.73. Results of the study also show that the personal assets of the women ranged from 5 to 500 thousand BDT with an average of 101.22 thousand BDT with standard deviation of 73.78 . 


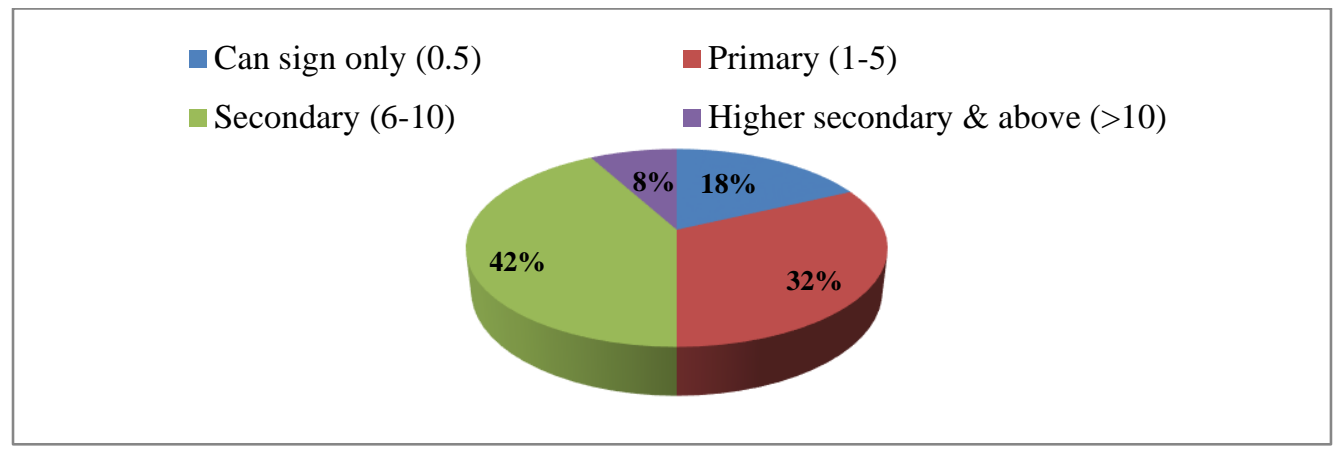

Figure 5: Distribution of the women based on their personal education

However, the score of communication exposure of the respondent rural women were ranged from 1 to 35 in against the possible score of $0-48$. The average communication score of the respondent women was 20.03 with the standard deviation of 5.42. The findings indicate that the respondent women have moderate communication exposure with various information sources. On the other hand, the score of the organizational participation of the respondents ranged from 1 to 10 next to the probable score of $0-12$. The mean organizational score of the respondent women were 4.92 and standard deviation was 1.14 (Table 2).

Table 2 also demonstrates that the score of women friendly environment of the respondent women ranged between 0 and 5 with a mean score of 2.54 and standard deviation of 0.97 . On the basis of scores given for their favorable environment, women were grouped into three categories as shown in Figure 6. Data illustrated in Figure 6 indicate that about two-thirds (72.3 percent) of the rural women had a score of moderately women favorable environment compared to 20 percent highly favorable and 7.7 percent poorly favorable environment. A comparatively moderate women favorable environment encouraged rural women to engage in many economic and social activities. Similar findings was reported by Hoque and Itohara (2008) and Parveen and Leonhauser (2004). Poor women friendly environment does not allow the women to work outside.

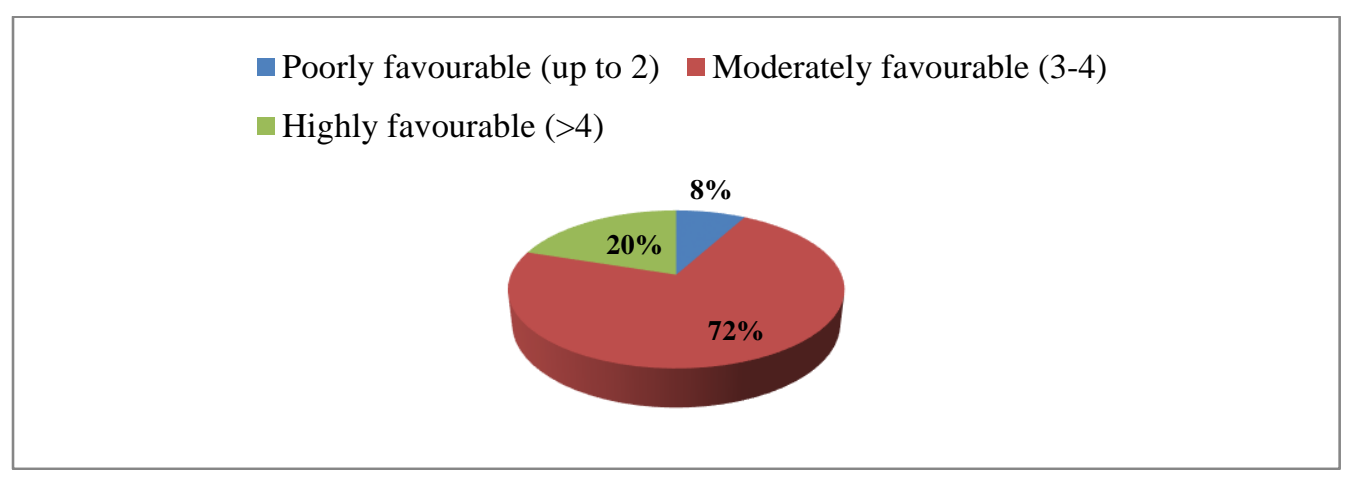

Figure 6: Distribution of the respondent women based the score of women friendly environment

\subsection{Economic empowerment of the rural women}

The main focus of the study was to evaluate the position of economic empowerment of the women with involvement in different IGAs. Table 3 shows that before introducing the participatory video programme women's participation in IGAs like safe food cultivation, vermi-compost preparation, botanical pesticide preparation and filming (video recording) was zero (0). However after joining with participatory video programme their participation was remarkable in the activities like safe food processing, handicraft preparation and homestead gardening also fewer than after participation. 
On the other hand, it is evident that after introducing participatory video program frequency of participation and percent in these sorts of activities was much more than before participation. Table 3 demonstrates that the highest bulk (70.76) percent of respondent women had participation in homestead gardening after joining with video programme while it was less than half (47.69 percent) before joining to video programme. Thus, data from the Table 3 clearly indicates that participation in homestead vegetable gardening has increased and leaded to enhance income of the women.

Table 3: Women's participation in economic activities

\begin{tabular}{|c|c|c|c|c|}
\hline \multirow{3}{*}{ Types of activities } & \multicolumn{4}{|c|}{ Number of participants $(n=65)$} \\
\hline & \multicolumn{2}{|c|}{ Before } & \multicolumn{2}{|c|}{ After } \\
\hline & Frequency & Percentage & Frequency & Percentage \\
\hline Safe vegetable cultivation & 0 & 0 & 42 & 64.61 \\
\hline Preparation of vermi-compost & 0 & 0 & 39 & 60.00 \\
\hline Botanical pesticide preparation & 0 & 0 & 33 & 50.77 \\
\hline $\begin{array}{l}\text { Filming(video recording of local } \\
\text { events) }\end{array}$ & 0 & 0 & 21 & 32.30 \\
\hline Safe food processing & 25 & 38.46 & 35 & 53.85 \\
\hline Handicraft preparation & 37 & 56.92 & 45 & 69.23 \\
\hline Homestead gardening & 31 & 47.69 & 46 & 70.76 \\
\hline
\end{tabular}

Thus, women's income was increased as compared to before participation in video programme. It was also revealed in Table 3 that like home gardening, participation of the women have increased significantly in safe food processing and handicrafts making those also contributed in their better income.

\subsection{Income improvement of the rural women due to participation in IGAs}

An inventiveness was taken to assess the sum of income got by the women from various sources and was presented in Table 4. The findings show that before introducing the participatory video programme income from safe food cultivation, vermin-compost preparation, botanical pesticide preparation and filming (video recording) was zero.

It was also evident that the women's income from safe food processing, handicraft preparation and homestead gardening also fewer than after income. On the other hand, after participation in video programme, income earnings of the women from such types of activities were also greater than before participation. Thus, data from the Table 4 clearly indicates that income of the women has improved significantly ( 11 to 120 thousand BDT) due to participation in IGAs as introduced by video mediated extension activities. However, findings show that the respondent women's economic empowerment was ranged between 3.5 to 23 thousand BDT.

Table 4: Income of the respondents from different economic actions

\begin{tabular}{lccc}
\hline Types of activities & Before & $\begin{array}{c}\text { Income (in '000' BDT) } \\
\text { After }\end{array}$ & Improvement \\
\hline Safe vegetable cultivation & 0 & 120.1 & 120.1 \\
Preparation of vermi-compost & 0 & 95.5 & 95.5 \\
Botanical pesticide preparation & 0 & 89.7 & 89.7 \\
Filming(video recording) & 0 & 58.9 & 58.9 \\
Safe food processing & 85.6 & 110.7 & 25.1 \\
Handicraft preparation & 120.4 & 134.5 & 14.1 \\
Homestead gardening & 105.5 & 116.6 & 11.1 \\
\hline
\end{tabular}

The mean economic empowerment score was 9.68 and standard deviation was 4.01. On the basis of the score attained the respondent rural women were grouped into three classes as shown in Table 5. 
Table 5: Allocation of the women based on their income improvement

\begin{tabular}{lcccc}
\hline Category & Frequency & Percent & Mean & SD \\
\hline Low (up to 5000 BDT) & 4 & 6.2 & & \\
Medium (5001-10000 BDT) & 37 & 56.9 & \multirow{2}{*}{9.68} & 4.01 \\
High (>10000 BDT) & 24 & 36.9 & & \\
Total & 65 & 100.0 & & \\
\hline
\end{tabular}

Data demonstrated in Table 5 indicates that the over half (56.9 percent) of the respondents had medium income improvement. Whereas more than one-third (36.9 percent) of the respondent women had high improvement and only 6.2 percent had low income improvement. Finding shows that highest majority (93.8 percent 0 of the respondent women had medium to high income improvement. As a result the women become more capable to contribution in household income as well taking part in family decision building methods.

\subsection{Contribution of rural women in household income}

The study also tries to determine the amount of contribution of the women into their household income. Figure 7 shows the differences between before and after contribution of the women in household income.

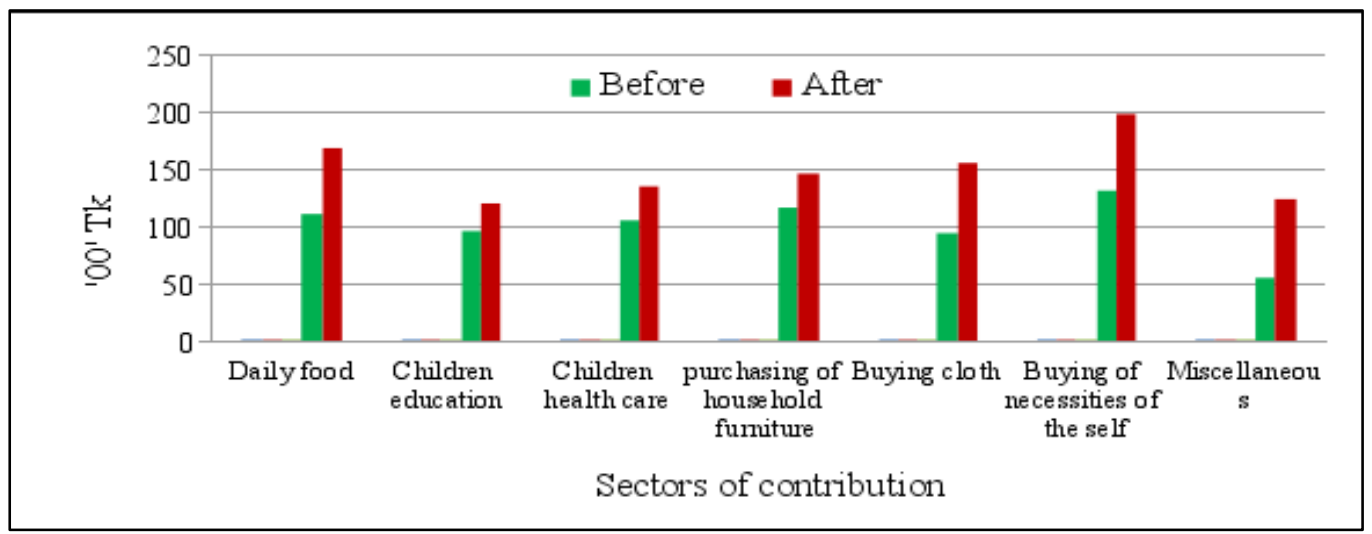

Figure 7: Bar graph showing contribution of women in household income ('00' BDT)

Figure 7 show that women's economic contribution has increased significantly in all family items of expenditures from food to buying women's self-necessities after joining in video programme. However, it is evident that women's dependency on male members for buying their personal necessities. Along sides, after contribution on buying cloth, purchasing of household furniture, children education, children health care and miscellaneous was also higher than before contribution. This difference is due to improvement of rural women's income. As their contribution in family income is increased so, they will be able to participate in family decision procedure.

\subsection{Participation of the rural women in family decision making process}

Data furnished in Table 6 shows that after improving income improvement women can contribute into household income and can participate in family decision making process on children education, children health care, spending money, buying and selling of land, buying of necessities, daily food menu, getting child, use of contraceptives and decision about self-issues (i.e., education, health, outgoing etc.). Among those areas of family decision making issues it is established that maximum women's participation (DI=140) was on decision about their self-issue and participation on getting child (DI=126), buying necessities ( $\mathrm{DI}=116)$, and use of contraceptives $(\mathrm{DI}=112)$ also higher than other sectors. 
Table 6: Case wise participation of the respondent women in family decisions

\begin{tabular}{lcccccc}
\hline $\begin{array}{l}\text { Aspects of Decision } \\
\text { making }\end{array}$ & $\begin{array}{c}\text { No } \\
\text { Participation }\end{array}$ & $\begin{array}{c}\text { Extent of Participation } \\
\text { Low }\end{array}$ & $\begin{array}{c}\text { Medium } \\
\text { Participation }\end{array}$ & $\begin{array}{c}\text { High } \\
\text { Participation }\end{array}$ & *DI & $\begin{array}{c}\text { Rank } \\
\text { order }\end{array}$ \\
\hline Child education & 0 & 10 & 12 & 25 & 109 & 6 \\
Child health care & 0 & 10 & 5 & 20 & 80 & 8 \\
$\begin{array}{l}\text { Spending money } \\
\text { Buying and selling of }\end{array}$ & 0 & 15 & 10 & 25 & 110 & 5 \\
land & 0 & 9 & 7 & 20 & 63 & 9 \\
$\begin{array}{l}\text { Buying of necessities } \\
\text { Daily food menu }\end{array}$ & 0 & 5 & 18 & 25 & 116 & 3 \\
$\begin{array}{l}\text { Getting child } \\
\text { Use of contraceptives }\end{array}$ & 0 & 8 & 15 & 19 & 95 & 7 \\
$\begin{array}{l}\text { Decision about self } \\
\text { issues (health, }\end{array}$ & 0 & 10 & 13 & 30 & 126 & 2 \\
education, outgoing) & 0 & 9 & 14 & 25 & 112 & 4 \\
\hline
\end{tabular}

*DI: Decision Index

However, Table 6 shows that women's least participation was on decisions of buying and selling of lands. Based on the level of participation on family decision making process the respondents rural women were classed into three classes like low participation (up to 9), medium participation (1018 ) and high contribution in the decision making process of the household issues $(>18)$ are shown in Table 7.

Table 7 shows that the level of participation score of the female members in the family decisions was ranged from 1 to 27 . The mean participation score on family decision making process was 21.63 and standard deviation was 1.83. Data presented in Table 7 indicates that the more than one-third (38.5 percent) of the respondent women belonged to low participation as contrast to 35.4 percent having high participation in family decision making process. While more than a quarter $(26.2$ percent) of the respondent rural female members had medium participation in family decision making process. Finding shows that more than half (61.6 percent) of the women had medium to elevated involvement in family decision making process.

Table 7: Distribution of the women based on their contribution in family decision making process

\begin{tabular}{lcccc}
\hline Category & Frequency & Percent & Mean & SD \\
\hline Low extent of participation (up to 9) & 25 & 38.5 & & \\
Medium extent of participation (10-18) & 17 & 26.2 & 21.63 & 1.83 \\
High extent of participation $(>18)$ & 23 & 35.4 & & \\
Total & 65 & 100.0 & & \\
\hline
\end{tabular}

As they are affable to contribute in family verdict process; so, the researcher indicate that rural women are economically empowered. This finding was also confirmed by Ferdoushi et al. (2011), Hoque and Itohara (2009) and Begum et al. (2000).

The crosstab shows that when income improvement is low then their involvement in household decision making process is also low and high participation is zero. Whenever, medium improvement in income indicates higher degree of contribution in household and lower partaking in family decision making process. It is apparent from Table 8, the higher the income improvement is higher the contribution in family decision making. 
Table 8: Crosstab between income improvement and contribution in household decisions

\begin{tabular}{lcccc}
\hline \multirow{2}{*}{ Categories on income improvement } & \multicolumn{2}{c}{ Extent of involvement in family decisions } & \multirow{2}{*}{ Total } \\
& Low & Medium & High & ( \\
\hline Low income improvement & 18 & 8 & 0 & 26 \\
Medium income improvement & 7 & 9 & 19 & 35 \\
High income improvement & 0 & 0 & 4 & 4 \\
Total & 25 & 17 & 23 & 65 \\
\hline
\end{tabular}

On the other hand when income improvement is low then women have also lower participation is in family decision making process. So, the crosstab clearly indicates that if income of the rural women is improved then their input in family decision making process about different family dealings would be much better.

\subsection{Relationship between economic empowerment of the rural women and their selected characteristics}

Single vital objective of the study was to identify the association between women's economic empowerment and their elected socio-economic characteristics. In this regard correlation coefficient ( $r$ ) was computed. The relationship between the dependent and independent variables are shown in Table 9. Data furnished in Table 9 shows that personal education, educational status of spouse/ household head, personal asset, communication exposure, organizational participation, women friendly environment" had a significant positive relationship with the status of women's economic empowerment.

Table 9: Relationship between characteristics of the rural women and their economic empowerment

\begin{tabular}{lc}
\hline Characteristics of the rural women & Coefficient of correlation $(\mathbf{r})$ with $63 \mathrm{df}$. \\
\hline Age $\left(\mathrm{X}_{1}\right)$ & $-.124^{\mathrm{NS}}$ \\
Personal education $\left(\mathrm{X}_{2}\right)$ & $0.521^{* *}$ \\
Spouse/household head education $\left(\mathrm{X}_{3}\right)$ & $0.378^{* *}$ \\
Personal asset $\left(\mathrm{X}_{4}\right)$ & $0.273^{*}$ \\
Communication exposure $\left(\mathrm{X}_{5}\right)$ & $0.511^{* *}$ \\
Organizational participation $\left(\mathrm{X}_{6}\right)$ & $0.565^{* *}$ \\
Women friendly environment $\left(\mathrm{X}_{7}\right)$ & $0.772^{* *}$ \\
\hline
\end{tabular}

Ns Not Significant

* Significant at 0.05 level **Significant at 0.01 level

On the other hand, age had no significant relationship with the status of women's economic empowerment. Naoroze (2004) and Sarker (2005) found the opposite result and concluded in their study so as to age of the rural women had no noteworthy affiliation with their empowerment. The positive association between the educational level of the rural female members and their economic empowerment is for the reason that higher educated women were more empowered than the lower and illiterate women. Education enhances empowerment by increasing access to new knowledge and information which help a woman to realize their ownership, to challenge injustice and discrimination, to change their outlook. Education enables an individual to become more socialized, to have a wider outlook, to fight against injustice and also to gain better knowledge about every sphere of life both from cultural and economic point of view of a society.

\section{CONCLUSION}

Results of the study exposed that mainstream of the rural women had intermediate to high income improvement due to participation in participatory video programme. It may be summarized that the majority of the rural female of the study area possessed positive income improvement status due to 
their greater participation in IGAs introduced by the video mediated extension programme. As a result they are becoming more proficient to donate in household income over and above can participate in decision making of their household affairs. The study explored that personal educational level of the rural women had affirmative and noteworthy correlation with their economic empowerment status. So, it may be recapitulated that rural women will be economically made powerful if they are properly educated. It is, therefore, recommended that different GOs and NGOs should take appropriate initiatives for mass literacy programme in order to increase knowledge, understanding and ability of the rural women for making them human resources rather than family burden. Communication media exposure had also significant and positive relationship with their economic empowerment. It leads to the conclusion that the rural women will be economically empowered if they get more information on IGAs through various communication sources. So, it is recommended that public sector extension service providers and concerned NGOs should undertake systematic communication campaign to provide timely and effective information to the women regarding various IGAs. Moreover, number of female extension workers should need to be increased in agriculture and allied developmental departments to facilitate easy interaction and required skills transfer to women client. The study also explored that affiliation of the women with various organization is very effective to improve their confidence and capacity for operating an IGA and getting necessary technical and financial support. Finally it can be concluded that participatory videos has effectively improved rural women's capacity to take part in IGAs and led to improve their income which ultimately contributed in improving rural women's empowerment. For viable rural growth it is essential to mainstream the rural female in development initiatives. To make it true special attention is needed from all concerned agencies.

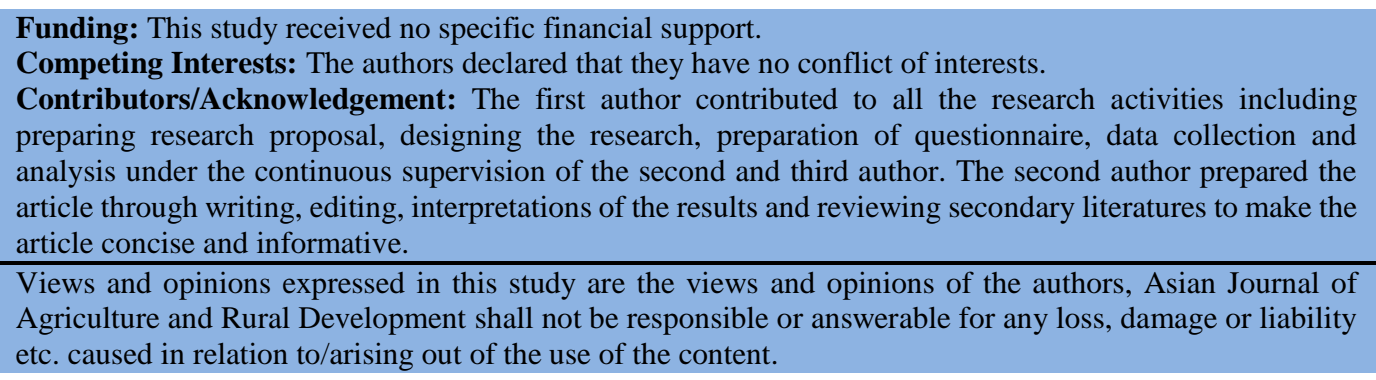

\section{References}

BBS. (2016). Statistical Year Book 2015. Bangladesh bureau of statistics. Ministry of Planning, Government of the People's Republic of Bangladesh.

Begum, H. A. (2005). Empowerment of women in Bangladesh: TMSS experience. Paper Presented at the Conference of "Beijing+10 Review and Appraisal" on Empowerment of Women in Bangladesh, Organized by United Nations Organization, New York, USA. February 28 March 11, 2005. view at Google scholar

Begum, I. A., Alam, M. L., \& Rahman, M. H. (2000). Decision-making and poverty alleviation potential of women practicing homestead agro-forestry enterprises. Bangladesh Journal of Extension Education, $11 \& 12(1 \& 2), 115-122$.

Bhaumik, U., Sen, M. H., \& Ghattergii, I. G. (1996). Participation of rural women in decision making. Indian Journal of Extension Education, 32 (1 to 4), 26-34. view at Google scholar

Biswas, T. K. (2002). Women's Empowerment and Demographic Change (An unpublished PhD Thesis), Department of Statistics, Jahangirnagar University, Bangladesh. view at Google scholar

Chowdhury, A. H., Akter, R., Pleoscheck, F., \& Sarker, M.A. (2011). Participatory rural video Centre -an approach to support learning and farmers' innovation in Bangladesh. Paper presented in Tropentag-2011, International Research on Food Security, Natural Resource Management and Rural Development, Hamburg, Germany. view at Google scholar 
Ferdoushi, A., Chamhuri, S., \& Nor, A. H. I. (2011). Contribution of rural women to family income through participation in microcredit: an empirical analysis. American Journal of Applied Sciences, 8(3), 238-245. view at Google scholar / view at publisher

GOB. (2015). The constitution of Bangladesh. Government of the people's republic of Bangladesh. Available at, http://bdlaws.minlaw.gov.bd/print_sections_all.php?id=367.

Hoque, M., \& Itohara, Y. (2008). Participation and decision making role of rural women in economic activities: a comparative study for members and non-members of the micro-credit organizations in Bangladesh. Journal of Social Sciences, 4(3), 229-236. view at Google scholar / view at publisher

Hoque, M., \& Itohara, Y. (2009). Women empowerment through participation in micro-credit Programme: a case study from Bangladesh. Journal of Social Sciences, 5(3), 244-250. view at Google scholar / view at publisher

Hoque, M., Sarker, M. A., \& Islam, M. T. (2010). Women's Participation in Economic Activities: a comparative study for members and non-members of the Micro-credit Organizations. Bangladesh Journal of Extension Education, 22(1\&2), 57-64. view at Google scholar

Kabeer, N. (2001). Reflections on the measurement of women's empowerment. In Discussing Women's Empowerment-Theory and Practice. SIDA Studies No. 3. Novum Grafiska AB: Stockholm. view at Google scholar

Kindon, S. (2003). Participatory video in geographic research: a feminist practice of looking? Area, 35(2), 142-153. view at Google scholar / view at publisher

Lunch, N., \& Lunch, C. (2006). Insights into participatory video: Ahandbook for the field. UK: Insight. view at Google scholar / view at publisher

MoWCA. (2016). Present status of women in Bangladesh. Ministry of women and children affairs, government of the people's republic of Bangladesh.

Naoroze, K. (2004). Rural women's empowerment through participation in aquaculture. M.S. (Ag. Ext. Ed.). Thesis, Dept. Of Agricultural Extension Education, Bangladesh Agricultural University, Mymensingh, Bangladesh. view at Google scholar

Papa, M. J., Singhal, A., Ghanekar D.V., \& Papa, W. H. (2000). Organizing for Social Change through Cooperative Action: The (Dis) Empowering Dimensions of Women's Communication. Communication Theory, 10(1), 90-123. view at Google scholar / view at publisher

Parveen, S., \& Leonhauser, I. (2004). Empowerment of rural women in Bangladesh: A household level analysis. Proceeding of the Conference on Rural Poverty Reduction through Research for Development and Transformation, Oct. 5-7, Berlin, Germany, pp: 1-10. Available at, http://www.tropentag.de/2004/abstracts/full/382.pdf.

Sarker, T. (2005). Empowerment of women beneficiaries under CONCERN Bangladesh. M.S. (Ag. Ext. Ed.). Thesis, department of agricultural extension education, Bangladesh agricultural university, Mymensingh, Bangladesh. view at Google scholar

UNDP. (1997). Human development report 1997. New York: Oxford University Press. view at Google scholar / view at publisher

UNDP. (2010). Hope in hard times: women's empowerment and development. United Nations Development Programme Human Development Reports Research Paper 2010/14, July 2010. view at Google scholar

Van Mele, P. (2006). Zooming - in zooming - out: a novel method to scale up local innovations and sustainable technologies. International Journal of Agricultural Sustainability, 4(2), 131-142. view at Google scholar / view at publisher

Zossou, E., Van Mele, P., Vodouhe, S. D., \& Wanvoeke, J. (2009). Comparing farmer-to-farmer video with workshops to train rural women in improved rice parboiling in central Benin. Journal of Agricultural Education and Extension, 15(4), 329-339. view at Google scholar I view at publisher 